\title{
SESCTV: por uma transgressão pela linguagem
}

Taís Rios Salomão de Souza

\section{Resumo:}

O SESCTV, canal de televisão administrado pelo SESC (Serviço Social do Comércio de São Paulo), caracteriza-se como uma iniciativa peculiar em seu âmbito midiático. Este estudo considera, especificamente, a maneira pela qual a grade de programação da emissora surge como fator determinante para a construção de sua linguagem. Neste sentido, busca-se uma visão analítica sobre seus fundamentos técnico-discursivos, de modo que sejam detectados, a partir dos fundamentos organizacionais e da disposição dos programas em grade, pontos de inovação ou respeito aos padrões vigentes. Trata-se de uma reflexão sobre um aspecto que pode influir decisivamente no posicionamento discursivo de uma emissora. E, no caso do SESCTV, é um ponto-chave para a consolidação do movimento inovador ao qual se propôs diante do meio televisivo.

\section{Palavras Chave:}

comunicação, SESCTV, linguagem, programação, televisão

\begin{abstract}
:
The SESCTV, television channel administered by the SESC (Serviço Social do Comércio de São Paulo), is characterized as an unique initiative in its mediatic scope. This study considers, in particular, the way in which a grid of programming of issuing emerges as factor to the construction of its language. In this sense, aims for an analytical vision above technical and discourse foundations, so are detected from the organizational foundations and the provision of programmes in grid, points of innovation or those standards. It is a reflection on one aspect that can decisively influence the positioning of a discursive issuing. And on SESCTV's case, is a key point for the consolidation of innovative movement to which it proposed before midday television.
\end{abstract}

\section{Keywords:}

communication, SESCTV, language, programming, television

O SESCTV iniciou suas operações oficialmente em 2 de maio de 2006. A emissora, que atua sob a legislação das emissoras de televisão por assinatura, é uma iniciativa do SESC São Paulo.

No entanto, a história do canal teve início a partir de administrações anteriores. O projeto original data do final de 1995, quando o SENAC (Serviço Nacional de Aprendizagem Comercial) viabilizou o projeto de um canal de televisão que visava ser apenas um circuito interno de conexão entre sucursais. A iniciativa desenvolveu-se até novembro de 1996, quando se tornou mais abrangente e culminou na abertura da TV SENAC.

A variedade temática dos programas contou com a ajuda do SESC, que, ao final dos anos 1990, passou a oferecer conteúdos para a TV SENAC. A parceria entre as duas entidades fortaleceu-se e foi oficializada em 2000 com uma nova sigla: STV. Neste contexto, SESC e SENAC passaram a dividir um orçamento anual de R\$ 18 milhões referentes à manutenção de equipamentos para transmissão do sinal, aluguel deste no satélite, produção e equipe. 
Todavia, em abril de 2006, foi oficializada a dissolução da STV, marcada pela saída do SENAC das atribuições de administração e produção. Dessa maneira, a partir do mês seguinte, o canal de televisão iniciou outra mudança, na qual passou a ser operado exclusivamente pelo SESC. A passagem de uma fase administrativa para a outra foi abrupta, não havendo um período de transição em que o modus operandi do canal pudesse ser apreendido. A nova administração assumiu e o empreendimento recebeu o nome de SESCTV.

O que não se pode negar é a proposta diferenciada inerente ao canal desde a sua idealização. No entanto, as conjunturas operacional e administrativa influíram severamente na constituição histórica da emissora e na consolidação do seu perfil de linguagem. Outro desafio sempre enfrentado pelo atual SESCTV é a questão do hábito e a configuração dos programas apresentados no que diz respeito à expectativa de alcance e apreensão por parte do público espectador. Estes e outros elementos - como a grade de programação, por exemplo fizeram da emissora uma experiência que em muitos pontos foge à trivialidade dos empreendimentos televisivos brasileiros. Por outro lado, as turbulências de sua trajetória abriram lacunas ainda não preenchidas se considerados os seus objetivos basilares. Aqui se busca analisar como o modelo da grade de programação pode influenciar o percurso da emissora com vistas à construção de uma estética discursiva realmente inovadora no cenário televisivo nacional.

\section{A grade de programação como parte do discurso}

Ao se consolidar como parte do hábito diário, a televisão sofisticou ainda mais os mecanismos de contato com o público. Para sistematizar a ocupação do cotidiano familiar, as emissoras racionalizaram esta aproximação ao criarem as grades de programação. Como bem elucida Soraya Ferreira (2004: 87):

A TV tem suas estratégias de programação baseadas em um ritual que podemos denominar como sendo o do calendário e o da repetição. É esse ritual que gera a audiência. A repetição ocorre na estrutura interna de um programa ou no fluxo da programação. Mas ela também se dá de maneira intertextual. Assim, um programa dialoga com o anterior e anuncia o que está por vir. As idéias de totalidade e de uniformidade de uma emissora se realizam por meio de uma estética que é aferida na repetição de signos, fórmulas, modelos de programas, cenários, personagens e enredos, cores, gestos e discursos, e por uma enunciação explicitamente semelhante entre as emissoras (diferentes canais e redes da televisão aberta e fechada), criando desta maneira linguagens repetidas.

Assim, o objetivo das grades concentra-se em duas frentes: a de organizar a cadeia produtiva e, também, a de informar ao espectador os horários dos programas. A grade de programação deve ser entendida como um instrumento posicionador da emissora no mercado, pois confere ao canal uma identidade visual, discursiva e comercial, além de proporcionar um melhor relacionamento junto a fornecedores (produtoras, por exemplo) e abrir espaço para uma autodivulgação sistemática. Isso tudo vinculado diretamente à manutenção, criação e fortalecimento de hábitos, modos de vida e consumo e opiniões. Ou seja, uma organização que não se dissocia dos objetivos discursivos das emissoras.

A 'metapropaganda' que se articula no âmbito das grades abre espaço para dois níveis por meio dos quais uma emissora busca legitimar-se. No nível que podemos chamar de tácito, o canal procura criar formas de sedução e fidelização que levem o telespectador a preferí-lo em detrimento dos demais. Isto ocorre nos diversos elementos componentes da linguagem que lhe é característica, desenhada de maneira que sustente tal estratégia. Já no campo explícito, figura a autopropaganda, em que a emissora exalta suas atrações e qualidades como empreendimento. Essa tática procura 'deslocar' a emissora como produtora de conteúdos de sua personalidade mercadológica, de modo que a segunda aja a favor da primeira e, com um aumento de 
público e receita, a primeira retribua à segunda. A grade de programação representa um planejamento que evidencia o principal objetivo do canal: fidelizar o espectador, de modo a fixá-lo por mais tempo diante dele, sobretudo quando é tamanha a facilidade de transitar entre os inúmeros disponíveis. A elaboração das grades de programação não é nova e remonta ao trabalho de Walter Clark (HINGST, 2004: 32), nas extintas TV Rio e Excelsior, quando implementou nos canais as modalidades horizontal e vertical, objetivando maior unidade à grade de programação e visibilidade aos programas, o que potencializava e abria espaço para a programação de venda - constituída pela veiculação publicitária.

Optar entre grade horizontal ou vertical configura-se como escolha que denuncia a estratégia e, com isso, o perfil fundamental de um canal televisivo. Hingst (2004: 30) explica que o módulo horizontal estabelece horários fixos para os programas durante toda a semana, enquanto que a programação vertical atribui uma seqüência às apresentações, conduzindo o telespectador a assistir um programa após o outro, em linearidade.

É certo que a escolha de determinado tipo de programação denota um posicionamento do canal, que na ânsia de fidelizar o espectador acaba por conciliar os dois conceitos, com maior predomínio da programação horizontal. Tal mescla é bastante comum nos canais abertos. Algumas vezes, o hibridismo surge justamente para privilegiar determinados programas, como é o caso da grade horária da Rede Globo em seu horário noturno. O canal adota a fórmula de exibir duas novelas intercaladas por um telejornal, de modo que um programa impulsione o outro. Conhecido como 'grade sanduíche', esse modelo explicita um hibridismo possível, dado que motiva a audiência de programas seqüenciais, mas mantêm fixos seus horários de exibição todos os dias. $\mathrm{O}$ encadeamento que se verifica na televisão aberta busca atender à estratégia comercial das emissoras no que tange à fidelização de público. O modelo eleito de grade predominante, portanto, age em benefício de uma linguagem utilitarista, posta apenas como meio de reforço das grandes corporações de comunicação.

\section{O modelo de grade e a produção de sentidos}

Por todas as relações que podem ser estabelecidas a partir da grade de programação, pode-se dizer que ela é uma das formas mais imediatas de se refletir sobre a produção de sentidos em um canal. A escolha da seqüência de programas, a forma como os intervalos - comerciais ou não - são preenchidos, as vinhetas de identificação do canal, bem como outros signos, são elementos que elucidam os padrões de linguagem adotados. Na maior parte das vezes - sobretudo na televisão aberta -, a significação dos canais parte da premissa de que estes são produtos, com subprodutos organizados de forma tal que lhes garanta atratividade comercial e em termos de audiência.

Padronizar a organização dos programas mediante uma determinada lógica representa claramente que há uma camada estratégica que pauta as ações do canal executante. Uma sistematização dita a lógica produtiva dos programas, que perpassa sua construção (filmagem, edição, dentre outras etapas) e o tratamento de seus conteúdos, de modo que, assim, forme-se um discurso e estabeleça-se um alinhamento concreto em relação aos preceitos determinados pelos setores executivos destas empresas.

[...] modelos são relevantes tanto na compreensão como na produção do discurso. Na produção, os modelos fornecem o tão necessitado 'ponto de partida' para construção de representações semânticas a serem expressas no discurso. Eles explicam parte das noções de 'intenção' e 'sentido pretendido' (DIJK, 2002: 163).

A paisagem audiovisual, à medida que se habitua com a adoção de modelos, caminha para um estado de 
às corporações de maior poderio econômico -, há um espraiamento de sua sistematização, de modo que haja uma repetição estratégica, a qual fundamenta uma busca pelos mesmos resultados teoricamente 'positivos' de uma emissora de larga expressividade.

Contudo, embora pressionados pela organização mercadológica criada em torno desta mídia, surgem vozes dissonantes - canais que arriscam a destoar dos sistemas já enraizados. Esta atitude diferenciadora sinaliza a possibilidade de uma variação no campo da linguagem e da própria significação carregada pela televisão. Como potenciais protagonistas deste movimento, figuram principalmente duas categorias: as emissoras público-educativas e de televisão por assinatura.

As primeiras surgem como potenciais transgressoras, em razão do compromisso social que lhes pauta. Além disso, o fato de não se vincularem diretamente a anunciantes permite que, de algum modo, sejam vistas como independentes e, portanto, livres para estabelecerem o padrão que a elas mais convém. Já os canais pagos, por estarem inseridos em um panorama de especialização e segmentação, encontram espaços para tratamentos diferenciados quanto ao fazer televisivo.

Em oposição a estas possibilidades, no entanto, há dois eixos essenciais - ambos conectados intimamente ao contexto mercadológico vigente: as grandes organizações e o hábito. As corporações dominantes buscam formas de minar iniciativas que se apresentem fora do escopo tido como "participante do padrão". Grandes empresas que não estão ligadas a qualquer emissora também se configuram como vitais para a sustentação de um canal público ou especializado. Sem apoiadores ou patrocinadores, raramente se vêem produções capazes de sustentar uma linguagem que, ao mesmo tempo, seja atraente e inovadora.

Isto se fecha pela questão da paisagem audiovisual, que nada mais é do que um hábito ao qual se acostumaram os telespectadores, sobretudo pela escassez de conteúdos contraditórios. Portanto, levam em conta que tal linguagem é a melhor possível. Além disso, toda a cadeia produtiva acostumou-se à lógica majoritária. Por isso, levar adiante um canal dissidente enfrenta barreiras institucionais, mercadológicas e, também, de hábito.

Uma das possíveis rupturas com o modo de produção predominante, por estar potencialmente a cargo dos canais educativos, é discutida por Felipe Pena (2001: 5). Ele levanta um debate acerca do papel dos canais universitários e enfatiza que a almejada pluralidade cultural (e, portanto, de linguagens) poderia ser viabilizada por meio das faixas temáticas na grade de programação, que pedem a organização do que é apresentado mediante o conceito vertical.

No caso, o autor recorta esse modelo apenas para os canais universitários. Contudo, observa-se que a adoção de tal é feita por canais cuja programação é orientada ao indivíduo e não ao posicionamento mercadológico. Cria-se o espaço para que esse indivíduo se insira direta ou indiretamente na produção, de modo que suas peculiaridades sejam tratadas de uma forma clara e apropriada, sem a influência de um discurso corporativo que desvirtue a valorização do humano. Para Bakhtin (1997), o ouvinte é ativo, dotado de uma atitude responsiva. Em uma transposição para o meio televisivo, por exemplo, pode-se tratar o telespectador como um interlocutor, que assiste às mensagens e signos componentes, apreende-os e significa o mundo a partir de seus próprios discursos - estes influenciados por aquilo que assiste. A TV SENAC, desde suas primeiras transmissões - e foi mantida durante toda a gestão da STV - já adotava tal modelo, o que demonstra, mais uma vez, que a grade de programação não apenas está intimamente relacionada ao modo produtivo do canal, como também o transparece. Moreira (2006, entrevista) justifica a escolha da grade:

A escolha da grade de programação está diretamente ligada ao perfil do canal. Trata-se, portanto, de um canal por assinatura, por isso escolhemos a grade vertical inclusive de acordo com o investimento que tínhamos. Se você tem muito dinheiro, você pode fazer uma grade horizontal, como as TVs 
abertas. Mas, se você tem outro tipo de orçamento, a grade horizontal é impeditiva e burra. Porque você não pode partir, principalmente do surgimento de um canal por assinatura, com a pretensão de competir por audiência. Não é essa a proposta. A proposta é cultural e educacional. Então, a gente optou pela grade vertical, mantivemos essa grade até onde foi possível. O SESC desde que entrou na parceria, em 2000, queria fazer grade horizontal e tivemos um enfrentamento interno por conta disso. Mas a grade horizontal na STV era inviável (MOREIRA, 2006, entrevista).

Um exemplo de grade de programação da STV, referente ao dia 01 de março de 2006, está abaixo. Ela mostra que os programas são agrupados por temáticas e objetivos, conferindo uma unidade àquele período de programação, chamado de 'Faixa STV'. Ao todo, são sete faixas, que se alternam durante a programação, podendo haver repetições de algumas. Essa repetição, no entanto, diz respeito apenas à temática proposta, visto que os programas que compõem as faixas não se repetem durante o mesmo dia, garantindo assim o ineditismo de cada período da programação.

Parte da grade de Programação ST V-01/03/2006

\begin{tabular}{|c|c|c|}
\hline \multicolumn{3}{|c|}{ FAIXA ST VEDUCAÇ ÄO E OPINIIÄO } \\
\hline$\infty$ hю0 & $\begin{array}{l}\text { O MUNDO DA } \\
\text { LITEATURA }\end{array}$ & UM OLHAR NO FUTURO \\
\hline $00 \mathrm{~h} 30$ & TRAMFOUM & D OC UMENTARISTAS \\
\hline $01 \mathrm{~h} 30$ & $\begin{array}{l}\text { RETRATOS - TV } \\
\text { HORIZONTE MG } \\
\end{array}$ & SÉRGIO MIRANDA \\
\hline $02 \mathrm{~h} \infty 0$ & $\begin{array}{l}\text { LEILA ENTREVSTA } \\
\text { - REDE MINAS }\end{array}$ & MÉXICO-MARLACHIS \\
\hline \multicolumn{3}{|c|}{ FAIXA ST VARTE E CULT URA } \\
\hline $02 \mathrm{~h} 30$ & $\begin{array}{l}\text { SALA DE CINEMA - } \\
\text { TV HORZONTE }\end{array}$ & MARTA NASSAR E JANUÁRIO GU ED ES \\
\hline \multicolumn{3}{|c|}{ FAIXA ST VCINEMA } \\
\hline $03 \mathrm{~h} \infty$ & CURTA STV & A MA CRIADA, DE SUNG SFAI \\
\hline $03 \mathrm{~h} 30$ & $\begin{array}{l}\text { O MUNDO DO } \\
\text { CINEMA } \\
\text { BRASILEIRO }\end{array}$ & A MÚSICA NO CINEMA \\
\hline \multicolumn{3}{|c|}{ FAIXA ST V EDUCAÇ ÄO E OPINIÄO } \\
\hline $04 h 00$ & $\begin{array}{l}\text { SINTONIA - TV } \\
\text { CÂMARADF }\end{array}$ & STEF AN CUNHA \\
\hline \multicolumn{3}{|c|}{ FAIXA ST VARTE E CULT URA } \\
\hline $04 h 30$ & $\begin{array}{l}\text { RE (COR TE) - TVE } \\
\text { BRASIL }\end{array}$ & MOACYR SCLIAR / MARGARETH MEN EZES \\
\hline $05 \mathrm{~h} \infty$ & $\begin{array}{l}\text { TUE REPORTER - } \\
\text { TUE RS }\end{array}$ & MU NDO DOS LNROS \\
\hline $05 \mathrm{~h} 30$ & $\begin{array}{l}\text { TV POVOS DO MAR } \\
\text { - ECOCINE USP }\end{array}$ & MANEJO SUSTEN TÁVE DA CAIXETA \\
\hline \multicolumn{3}{|c|}{ ESPAÇO VISÖES } \\
\hline $06 \mathrm{~h} 00$ & VISỐES DO MUNDO & $\begin{array}{l}\text { HERMANCE CARRO /F LOR DE ABOBRINHA } \\
\text { REC HEADA COM QUINOA }\end{array}$ \\
\hline \multicolumn{3}{|c|}{ FAIXA ST VMÜSICA E DANÇA } \\
\hline $06 h 30$ & $\begin{array}{l}\text { TVE BAHIA } \\
\text { ESPECIAL }\end{array}$ & BANDA SOMA \\
\hline $07 \mathrm{~h} 30$ & $\begin{array}{l}\text { VIOLABRASIL - TV } \\
\text { HORIZONTE }\end{array}$ & ORQUESTRA MIN AS E VIOLA - I \\
\hline $08 h \infty$ & $\begin{array}{l}\text { PALCO BRASIL - } \\
\text { REDE MINAS } \\
\end{array}$ & GERALDO AZEVEDO \\
\hline$\infty \mathrm{h} \infty$ & RITMOSE SONS & $\begin{array}{l}\text { NOVO CAN TO: ARRANCO DE VAR SÓVIA/NILZE } \\
\text { CARVALHO/MARQUINHOS }\end{array}$ \\
\hline \multicolumn{3}{|c|}{ FAIXA ST VARTE E CULT URA } \\
\hline $10 h 00$ & $\begin{array}{l}\text { BOULEVARD - TVE } \\
\text { BRASIL }\end{array}$ & $\begin{array}{l}\text { MARILIA FERA / AMIR LABAK /JO } \% \text { O MOREIRA } \\
\text { SALLES }\end{array}$ \\
\hline $10 h 30$ & $\begin{array}{l}\text { MUSEUS } \\
\text { BRASILEIROS }\end{array}$ & MU SEU AEROESPACIAL - RIO DE JANEIRO \\
\hline \multicolumn{3}{|c|}{ FAIXA ST VEDUCAÇ ÄO E OPINIÄO } \\
\hline $11 \mathrm{~h} \infty \mathrm{O}$ & $\begin{array}{l}\text { NA ONDADO } \\
\text { SENAC }\end{array}$ & HOTELARIA \\
\hline $11 \mathrm{~h} 30$ & $\begin{array}{l}\text { PROGRAMA DE } \\
\text { PALAVRA }\end{array}$ & RASTAFÁRI \\
\hline \multicolumn{3}{|c|}{ FAIXA ST V CIDADANIA E QUALIDADE DE VDA } \\
\hline $12 \mathrm{~h} \omega 0$ & GERAÇÕ̃ES & POLITITCAS CULTURAIS \\
\hline $12 \mathrm{~h} 30$ & $\mathrm{CHECK}-\mathrm{UP}$ & DIVERTICULITE \\
\hline $13 h \omega 0$ & VIVA VID A & JUDÖ \\
\hline
\end{tabular}

Assim como a maior parte dos canais por assinatura, a base da programação é feita com reprises. De acordo com a grade de programação exposta acima, o programa era exibido pela primeira vez em horário preferencial 
e, depois, apresentado por mais seis vezes seqüencialmente durante uma semana em horários diferentes. Isso mostra que as faixas mudavam de horário - e, portanto, de ordem - todos os dias, pois, como menciona Moreira (2006, entrevista), a grade vertical servia para que a "pessoa se agendasse para ver o programa que ela quisesse. Importante é que ela visse o programa, não importasse o horário". Ele ainda continua o raciocínio e conclui que:

A grade horizontal tem um defeito de origem: ela escraviza o telespectador. Ela condiciona hábitos. Então, por isso, também a gente acreditava que estava inovando no fazer televisão. E a grade vertical é fundamental para isso, para criar alguma coisa nova. Quando você coloca a grade horizontal, você se iguala a todos (MOREIRA, 2006, entrevista).

Pode-se dizer que a STV, em uma primeira análise, optou pela orientação ao indivíduo, condicionando sua organização produtiva a partir de um prisma educativo-cultural que atendesse, de algum modo, às demandas de enriquecimento e fortalecimento crítico do telespectador. No entanto, é temerário afirmar que tal escolha foi inovadora. Pouco é sabido se a opção pela grade vertical ocorreu por conta do baixo orçamento disponível ou por uma real propensão a adotar tal viés de linguagem independentemente dos recursos financeiros à mão.

Eu que criei essas faixas com dois objetivos: o primeiro, era fazer com que o telespectador da STV tivesse a oportunidade de se fidelizar ao que ele assistia [...] até porque nunca se teve a pretensão de ter gente assistindo à TV 24 horas por dia [...]. Então vamos facilitar: vamos agrupar os programas por temas. [...] O outro objetivo era que, como a TV era subsidiada pelo SENAC e pelo SESC e tinha um orçamento fechado e curto para fazer o que gostaríamos de fazer, a faixa foi criada para estimular patrocinadores. Então, se você pega um patrocinador, [...] ele patrocina três horas de programação e não só intervalos. [...] Mas o objetivo principal das faixas era em relação ao telespectador, para que ele pudesse assistir melhor à TV de que ele gostava (MOREIRA, 2006, entrevista).

A partir do momento em que o canal ficou a cargo somente do Serviço Social do Comércio, houve uma significativa modificação na linguagem da emissora: adotou-se a grade horizontal, sempre defendida anteriormente pela nova entidade mantenedora. Como se pode notar abaixo, não existe mais um agrupamento temático de programas.

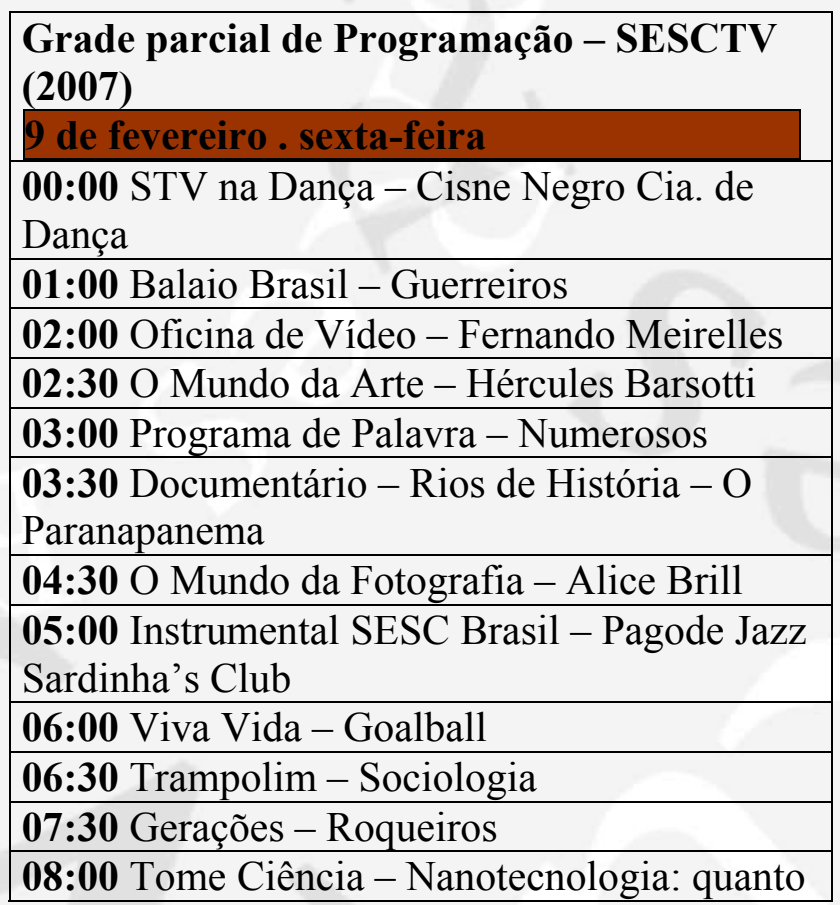




\begin{tabular}{|l|}
\hline menor, melhor \\
\hline 09:00 Filhos - Dilemas de família \\
\hline 09:30 Bem Brasil - Max de Castro \\
\hline 11:00 Fragmentos - São Miguel Paulista \\
\hline 11:30 Reportagem - O clima na terra \\
\hline 12:30 Visões do Mundo - Acidente \\
\hline
\end{tabular}

A verticalidade aproxima os programas de temas congêneres, de modo que o telespectador possa acompanhar, em horários próximos, apresentações cujos motes são semelhantes. As preferências de assunto tornam-se vizinhas, arranjadas em blocos. No entanto, tal proposta choca-se com o hábito consolidado do telespectador, que pauta sua rotina televisiva pelos horários e não por pontos de interesse.

Já a horizontalidade facilita o referenciamento por horários. Todavia, impossibilita o indivíduo de ter contato com programas que são exibidos em momentos nos quais sua rotina está obrigatoriamente ocupada com outras atividades - como as profissionais, por exemplo.

Desde que o SESC assumiu o controle da emissora, as produções foram interrompidas para a verificação de contratos com as empresas responsáveis pelos programas. Por isso, teve início um período em que a grade foi preenchida somente com reprises. Quando isto acontece no modo horizontal, elas esgotam-se em um período muito mais curto. Tomando como exemplo uma série de 52 programas, como 'Filhos', em vez de durar um ano - o que ocorreria mediante a verticalidade -, expira em menos de dois meses, dado que se torna refém de horários fixos. A cada dia, é obrigatória a exibição de um episódio diferente, o que faz a série esvair de forma acelerada.

Curiosamente, tanto o diretor de programação à época da STV como o atual, Walter Vicente Salles, consideram que os modelos por eles defendidos (vertical para Moreira e horizontal para o segundo) aumentam a fidelidade dos telespectadores. Isto abre caminho para uma outra reflexão, que diz respeito ao público a ser atingido. Caso o SESCTV proponha-se a edificar sua audiência mediante o incentivo à potencialização da criticidade, não se pode tornar os indivíduos reféns da rotina imposta pelos grandes padrões televisivos. Além disso, a formação do senso crítico demanda diálogo e, por isso multiplicidade de temas e opiniões. Em uma orientação vertical, isto se dá com mais intensidade, dada a aproximação das pessoas em relação aos assuntos, uma vez que estes vão ao encontro das pessoas no horário em que elas podem efetivamente ter contato com eles. No modo horizontal, existe um diálogo monocórdio entre o interlocutor e a emissora, em que o hábito diário acaba por predominar acima de qualquer outro valor.

A verticalidade da programação à época da STV auxiliava, ainda, na compreensão semântica dos programas, dado o agrupamento temático que se formava. Além disso, abria um potencial de ampliação do relacionamento entre emissora e interlocutor no que toca à interatividade. Se a televisão é composta por imagens e som, sendo que as primeiras são sempre assimiladas mais rapidamente do que o segundo, a programação visual deve ser considerada como um dos elementos que faz parte da comunicação do canal com o espectador, uma via de concretizar a interação pela linguagem. Como esclarece Koch (1995: 29):

Quando interagimos através da linguagem (quando nos propomos a jogar o 'jogo'), temos sempre objetivos, fins a serem atingidos; há relações que desejamos estabelecer, efeitos que pretendemos causar, comportamentos que queremos ver desencadeados, isto é, pretendemos atuar sobre o(s) outro(s) de determinada maneira, obter dele(s) determinadas reações (verbais ou não verbais).

As faixas de programação da STV facilitam a interação pela linguagem de modo que formam subunidades ou núcleos de sentido ao agruparem programas cujas temáticas e formatos são semelhantes. Em cada núcleo, 
inseridos e compõe, junto à programação dos demais núcleos, a unidade de sentido, o discurso do canal. Esta passagem é bastante nítida nas vinhetas institucionais que ilustram a temática da faixa. Como exemplo, pode ser mencionada a exibição de um passo de capoeira para a faixa Música e Dança ou o movimento de um trapezista para a faixa Arte e Cultura.

Outro aspecto de relevância consiste no advento da sólida interatividade, ou seja, do laço enriquecido entre espectador e canal, que é um dos contributivos essenciais para a proposta teórica do SESCTV de focar sua produção no desenvolvimento do humano sob uma perspectiva mais ampla. Isto diz respeito tanto ao diálogo como à formação crítico-educacional do cidadão. Uma comunicação na qual os sujeitos são ativos e plurais resulta em construções de conhecimento muito mais solidificadas.

É só na medida em que este reconhecimento se dá que a autoconsciência se torna possível, permitindo a comunicação, a interação por meio da linguagem, ou seja, a constituição do sujeito do discurso. $\mathrm{O}$ sujeito do discurso é assim resultado de um processo de formação que é fundamentalmente um processo cultural, de socialização (MARCONDES, 1996: 434).

A construção de uma emissora que transcenda os padrões vigentes requer uma outra abordagem junto ao telespectador. Em termos de conteúdo, não se pode perder de vista a contextualização deste público, de modo que haja um contato sincrônico no que tange à sua realidade. A comunicação interativa pressupõe uma troca verdadeiramente rica, com trânsito de diferentes significados e significações mediante diferentes visões de mundo. Modificar estes parâmetros representa transformar linguagem. O primeiro passo, sem dúvida, está no questionamento de como ela está sistematizada, como se pode detectar na análise dos formatos de grade. Sem dúvida, o que mais se aproxima desta relação pautada pelo plural é o horizontal.

\section{Considerações finais}

No caso específico do SESCTV - que se propõe em sua nova jornada institucional a romper algumas barreiras tradicionais - existe a possibilidade de discutir sua estrutura a partir de fundamentos básicos, como é o caso da grade de programação. Ainda se pode considerar a iniciativa do canal como algo embrionário, embora já demonstre frutos relevantes. Porém, cabe uma revisão aprofundada acerca do modelo de disposição dos programas ao longo da grade.

Por ser essencialmente estruturante, o modelo de organização das produções determina qual o rumo estético a ser seguido pela emissora. O modelo horizontal, sendo ele um símbolo do que se verifica na maioria das produções televisivas, naturalmente abre espaço para uma adequação das exibições à rotina privado-urbana do público espectador. Nesse sentido, núcleos de maior ou menor audiência formam-se naturalmente e o canal passa a ser mais um fragmento de uma agenda diária pautada por inúmeras atividades. Dessa forma, é englobado pelo cotidiano e exerce mera figuração mediante as demais tarefas.

Obviamente que pode haver uma compensação pelo conteúdo, ou seja, por mais que o modelo adotado seja o horizontal, a linguagem das produções pode, individualmente, inovar em inúmeros aspectos. Como afirmado anteriormente, uma opção não anula a outra, mas a influencia fortemente, dado o relacionamento em cadeia entre os componentes da linguagem televisiva.

Já o modelo vertical deixa de ser um alicerce meramente coligado ao tempo e passa a ser, naturalmente, um agente de conteúdo, uma vez que valoriza as temáticas e evidenciam muito mais explicitamente aquilo que a emissora pretende transmitir. Uma organização que é simultaneamente lógica e procura atrair públicos cativos de acordo com o assunto abordado. A quantidade de espectadores não se apresenta como fator primordial. As 
estatísticas cedem espaço à priorização qualitativa da audiência.

O SESCTV, como empreendimento que se propõe a transcender os limites da trivialidade no que tange à linguagem, deve, primeiramente, contemplar sua estrutura mediante uma visão abrangente, não restrita apenas a questões de conteúdo e formatos de programas e vinhetas. O locus analítico deve ser dimensionado de modo mais largo, uma vez que uma eventual transcendência começa nos elementos mais periféricos, como é o caso da grade de programação. Além dos movimentos de ruptura em artes gráficas, dramaturgia, documentários, discursos, dentre outros aspectos, a verticalidade necessita exercer seu protagonismo neste macrocenário. É, sem dúvida, o primeiro passo para que as produções ocupem seus lugares de maneira plena dentro deste ambiente tão propício para mudanças como é o do SESCTV.

\section{Bibliografia:}

BAKHTIN, Mikhail. Estética da criação verbal. São Paulo: Martins Fontes, 1997.

BEZERRA, Paulo. Polifonia. In: BRAIT, Beth (org.). Bakhtin: conceitos-chave. São Paulo: Contexto, 2005. p. 191-200.

BRITTOS, Valério Cruz. A oligopolização do mercado brasileiro de televisão por assinatura. In: XXII Congresso Brasileiro de Ciências da Comunicação, 1999. Disponível em: www.intercom.org.br/papers/xxiici/gt09/09b01.PDF. Acesso em: 01/03/2006.

DIJK. Teun Adrianus van. Cognição, discurso e interação. 4a . ed. São Paulo: Contexto, 2002.

DUARTE, Elizabeth Bastos. Reflexões midiáticas: o texto televisivo. In: Asociación Latinoamericana de Investigadores de la Comunicación (Alaic), 2000. Disponível em: www.eca.usp.br/alaic/chile2000/11\%20GT\%202000Discurso\%20e\%20Comunic/. Acesso em: 20/01/2007.

FERREIRA, Soraya. “A estética da repetição na televisão". Líbero, São Paulo, Ano VII, n 13-14, 2004. p.8695. Disponível em: www.facasper.com.br/pos/libero/libero13/86-95.pdf. Acesso em: 19/01/2007.

HINGST. Bruno. "Uma visão histórica da televisão". Líbero, São Paulo, Ano VII, n 13-14, 2004. p. 24-39. Disponível em: www.facasper.com.br/pos/libero/libero1

\section{Mini Currículo :}

Mestre em Comunicação Social pela Universidade Metodista de São Paulo. 